\title{
PROMOTING GRADUATE AND PROFESSIONAL ATTRIBUTES BY COORDINATING KOLBIAN REFLECTIONS FOR INDUSTRIAL DESIGN AND ENGINEERING STUDENTS
}

\author{
M. Mina ${ }^{1, \bigotimes}$, J. Cowan $^{2}$, N. D. Fila ${ }^{1}$ and W. S. Theh ${ }^{1}$ \\ ${ }^{1}$ lowa State University, United States of America, ${ }^{2}$ The Open University, United Kingdom \\ $\triangle$ mmina@iastate.edu
}

\begin{abstract}
This work features challenges of using integrated reflections in undergraduate Industrial Design and Engineering. Reflection activities can be challenging for the students and hard to implement in design and engineering classes. This report has two goals. The first is to introduce a process for more successful engagement for the students in problem solving and design. The second is to show that the process has validity and usefulness for Industrial Design students who are in a College of Design.
\end{abstract}

Keywords: design learning, industrial design, reflection, experimentation

\section{Introduction}

The growth and enhancement of a person is a lifelong journey. Explicit commitment to reflective development is a useful tool to enable them to develop the professional, experimental, and growth attributes that are needed for lifelong learners. Consequently, all attempts to enhance students' understanding and practice of reflection, and understanding how they think, how they make decision, and how they learn, are important contributions to learners' development. For this purpose, reflective practice has become well established in engineering and design education over the years (Quayle and Paterson, 1989; Sepp et al., 2015). Engineering and design educators have introduced varied reflection activities within their courses, for a variety of purposes (Quayle and Paterson, 1989; Sepp et al., 2015; Turns et al., 2014). These interventions resonate with the reflective nature of (engineering) design practice, and the power of reflection in supporting professional skill development (Svarovsky and Shaffer, 2006). Moreover, widespread efforts within and across institutions, such as the Consortium to Promote Reflection in Engineering Education (CPREE) and University of Edinburgh's Reflection Toolkit, continue to promote opportunities for reflective practice to support learners' development Despite the focus on reflective practice throughout engineering and design education, scholars have noted limited connections to established and integrated frameworks that can support more thorough, meaningful, and lifelong practices (Turns et al., 2014). In this paper we present and explore the use of an extended Kolb cycle for reflection by engineering and industrial design students. The authors have previously discussed and presented evidence that engineering educators can successfully utilize explicit reflective developments to enhance desirable graduate attributes/professional formation and provide lifelong learning (Mina and Cowan, 2019). Here, we extend the Kolbian model and investigate its relevance to design practice among industrial design students. 
The paper presents the challenges of utilizing the Kolb Cycle, and then provides a refined version of the cycle that has successfully stressed the Deweyan cycle of inquiry and active experimentation to benefit the students' journeys. Finally, the paper presents a study of industrial design students' perspectives on using the refined Kolb cycle within their design practice.

\section{The review of the cycles}

As reflective practitioners, we provide many opportunities for our students to engage in the cycle of inquiry and reflection. However, there are some shortcomings in the process that can hinder the learners' growth. This is true for both design and engineering students. Each group has unique ways of approaching reflective practice. In our extensive experiences as engineering and design educators we have observed that design students are more adaptable to the reflective process, while engineering students need more time to adjust. Our experience indicates that dedicated practice and instructor encouragement can improve engagement for all students (Cowan, 2006; Mina et al., 2015; Mina, 2015; Cowan, 2004).

Learning and design experiences are iterative processes and can be constructively linked to reflective activities leading to reasoned judgements. Accordingly, we offer an integrated path to self-managed reflective development of the learners' growth, facilitated by teachers. We briefly review challenges reported for the promotion of reflective practice in Engineering and Industrial Design education., and suggest how to circumvent them.

\section{Reflection for learning and development}

We regard reflection as a form of thinking in which a learner identifies and searches for answers to questions that have meaningful and practical use for them. Consequently, the reflective learner draws on past actions, in order to bring about future improvements (Hatton and Smith, 1995). This pedagogy has been established through keystone works in design practice, education, and professional development over the last 40 years (Boud et al., 1985; Bourner, 2003; Cross, 1982; Kolb, 1984; Schon, 1984). Five critical challenges remain to establishing reflective practice among engineering and design students and were identified in a previous study (Mina and Cowan, 2019).

\subsection{Challenges with reflective practice}

\subsubsection{Ambiguous definitions of reflection}

In "How we think", Dewey (1910) stressed that reflective thought originates in doubt or perplexity and promotes searching, inquiring and self-questioning. This process embodies intention to enhance practice. So, reflection begins from searching, questioning, and interrogating one's own experiences. This leads to identification and resolution of issues and challenges that need more in-depth attention (Bourner, 2003). Many definitions of reflective learning are generally formulated, can be unclear (Boud and Walker, 1998; Hanson, 2011), and may have considerable ambiguity (Thompson and Pascal, 2012) between contrasting pedagogical theories (Williams and Grudnoff, 2011). Consequently, for many learners the process is vague, and at times seems without potential value (Zhu, 2011; Bulpitt and Martin, 2005).

\subsubsection{Learners are unclear about what is expected of them in being reflective}

According to Morton (2009), learners can be unclear about what their reflections are expected to address. In many cases learners lack adequate instruction about why or how to reflect (Bulpitt and Martin, 2005; Ryan, 2010). Some educators provide a list of trigger questions, but the criteria to be met are not clear to the students.

\subsubsection{The abuse of the kolb cycle}

While the Kolb cycle (Figure 1) has been applied across engineering and design education settings, is often truncated by students when applied to their own practice (Figure 2). The key element of active experimentation, stressed by Dewey (1910), is often in short, students usually think about their experience and confidently leave their conclusion untested. 


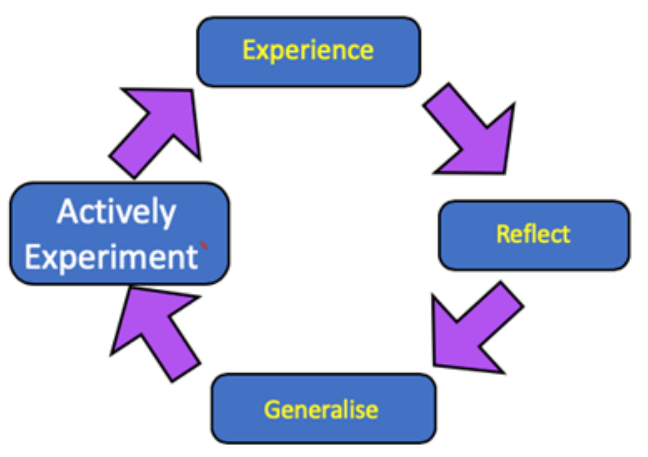

Figure 1. The classical kolb cycle

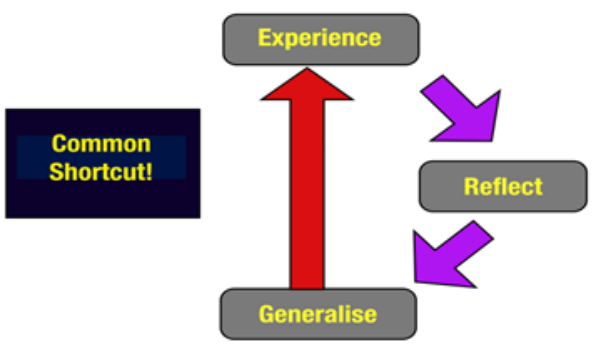

Figure 2. The "kolb cycle" as often practiced

O'Connell and Dyment (2011) reviewed more than 75 articles finding that most students' reflections comprised descriptive accounts, with limited or no reflection. Evidence-based claims of development were rare. Consequently, Samuels and Betts (2007) identified the need to move learners' reflections beyond description to analysis, deconstructing what had happened and why, and enabling them to constructively consolidate development.

The neglect of active experimentation is especially regrettable since it creates a void in the cycle of deeper thinking and inquiry that can help students learn from experiences and reflections thereon. Scholars have discussed this. Day (1993) criticized Schön's "failure" to consider the discursive, dialogical dimension of learning. Samuels and Betts (2007) stressed that reflection on experience is an insufficient condition for learning. They pointed out that self-questioning is needed to ensure "rigor" in formulating conclusions and in further planning by the reflector. It seems logical and in accord with established scientific principles to test out any hypothesized generalization, disproving, confirming or refining it during a further relevant experience.

\subsubsection{Positioning reflection towards more meaningful goals}

There is an increasing worldwide expectation that higher education should concentrate on employability. In a radically different approach to teaching and assessment, Yorke and Knight (2006) re-examined the need and means to embed graduate attributes and capabilities within curricula featuring complex learning. Often the compounded true outcomes are not externally measurable but do feature important aspects of learning and development to which learners have direct access, requiring. assessment to be centred on data self-reported by the students (Knight et al., 2003).

In a properly aligned curriculum, suitably planned activity should enable learners to achieve declared outcomes that are confirmed by appropriate assessment. Current programs rarely demand reflective activity to be aligned to explicit outcomes featuring graduate attributes and employability. In many cases, assessment is of the process of reflection rather than its outcomes. Our educational goal is to promote assessment of practice that aligns with evidence of students' professional awareness. We focus on the identification, choice, specification and pursuit of relevant attitudes by the learners, hoping that 
they would understand their benefits for lifelong learning. Additionally, we strive to develop a process that students understand and whose benefits they realize. However, learners' goals should also be focused on reflective achievement of outcomes that are attractive to employers. Learners can have difficulty understanding any beneficial outcomes from their reflective efforts. Thus, we refer the identification, choice, specification and pursuit of relevant graduate attributes to the learners themselves. This strengthens the students' engagement and awareness of the importance of such attributes.

\subsubsection{Reflections are not comprehensively structured or co-ordinated}

Moon and others (Moon, 1999b; Mälkki and Lindblom-Ylänne, 2012) rated transformative outcomes featuring a deliberately considered fresh intention by the learner, as the most valuable elements of being reflective. Due to the lack of coordinated course structure that promotes beneficial and constructive reflections, most learners do not appreciate the consequence of the absence of a coordinated structure. Consequently, most learners do not see reflections as beneficial component of their curricula. However, with careful program structure, faculty encouragement, and constructive design of curricula, we can encourage students to benefit from immediate alignment of the reflection in the program (Brockbank and McGill, 1998). This is possible with a proactive facilitator who encourages students to engage in intermental dialogue (Canning and Callan, 2010). This process can facilitate learners to seek counterexamples, to find, and resolve contradictions, doubts and dilemmas (Zeichner and Liston, 1996). The literature recommends that this is best achieved through encouraging and persuading (Bruner, 1986; Bain et al., 2002; Cowan, 2013) rather than forcing, or force feeding (Ashton and Elliot, 2007).

Smyth (1989) proposed a 4-stage framework for reflection-on-action, apparently abstracted without attribution from Zeichner and Liston (1996), but without provision for active experimentation to validate tentative conclusions. Williams and Grudnoff (2011) argued for further self-questioning steps to discourage merely narrative accounts, and to encourage consciously searching questions without planning to obtain answers. Following Vygotsky (1986), who advised that "thought is not begotten by thought; it is engendered by emotion", emotional matters are also incorporated. Hence, structuring of reflection as described in the literature mainly concentrates on reflection-on-recent-action. In our scheme, we seek to constructively integrate reflective forward planning, with an overall purpose in mind.

\section{Integrated and constructive reflections}

We have identified well-established stages in reflection that are commonly encountered by learners. We describe how these can be linked together, as opposed to being isolated within the program, to have better results.

An integrated approach features the reflector's varied questioning, being uncertain about what to do, or how to proceed. When thinking on how to engage with the reflecting questions, learners would be well advised seek advice (Harrison et al., 2005). As they move between different stages of learning, they should generate different type of questions for different type of learning outcome.

- Reflection-for-action Cowan (2006) anticipates forthcoming activity and its demands, and identifies possible options worthy of the learner's attention, deliberating between such possibilities through questioning and comparing them (Van Manen, 1991). This reflection can be equated with clinical forethought, seeking an outcome in the form of a viable forward plan. Typical questioning in this mode could include: What are the challenges immediately ahead of me? How should I tackle them?

- Reflection-in-action was described, with detailed examples, by Schön (1987). It entails being suddenly conscious, at the time, of what one is doing and how one is doing it, with immediate appreciation or learning (Thompson and Pascal, 2012). Typical questioning in this mode may include: What just occurred to me? Can I use that in future? How?

- Reflection-on-action is a common practice in employment and educational programs (Moon, 1999b). Reflective review of an experience is undertaken while searching for transferable learning and understanding (Zhu, 2011). A typical question at this stage would be: What can I learn from this experience which should make me more effective in situations like this than I have been in the recent past? (Cowan, 2006). 
- Composting reflections (Cowan and Stroud, 2016) entails reflectively revisiting past experiences and reflections thereon (Moon, 2004). Learners can make conscious efforts to dig up, turn over and transform the now-composted earlier reflections. This can yield fruitful thoughts or undeveloped thinking with rich potential to nurture the learner's present agenda. They contribute to what Moon had earlier called multiple layer reflection (Moon, 1999a). A typical question in this mode is: Is this useful to my present development planning?

\section{Integrated reflections}

We suggest that all four reflective approaches can be rationally and usefully linked together as shown in Figure 3.

Learners have been asked to identify and plan to address at least three valued graduate or professional capabilities which will be expected of them (Francis and Cowan, 2008; Quilligan et al., 2017). The choice and planning should emerge from reflection-for-action, informed (if they have gone through the cycle previously) from composted reflections. Thought should be given to gathering data to inform monitoring and ultimate evaluation, which the program expects.

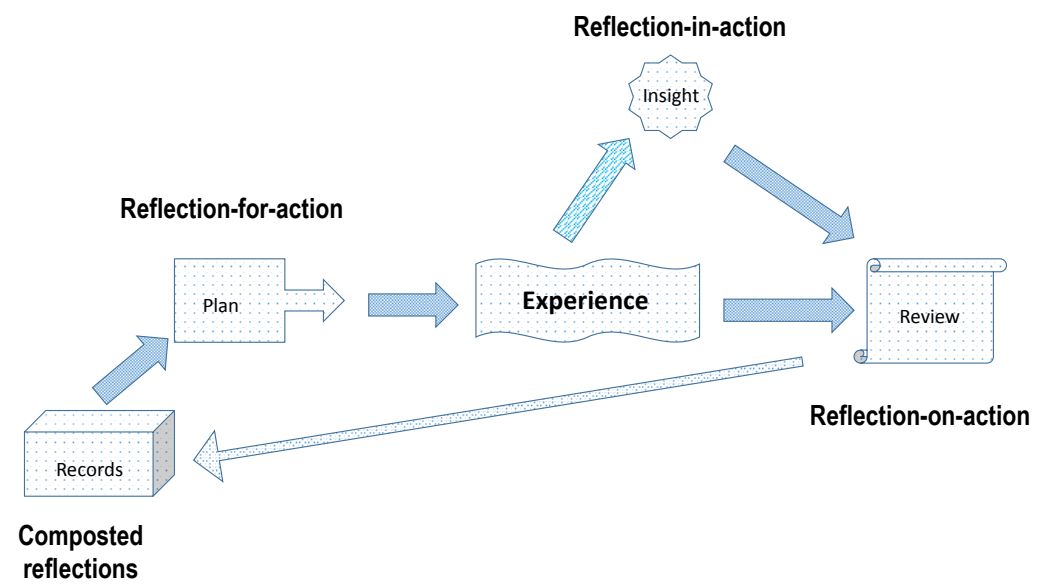

Figure 3. Integrated reflections

Reflections-on-action naturally concentrate primarily on progress towards the predetermined aims. It will nonetheless also identify and analyse other relevant aspects of the experience. In due course, reflection-on-action, whether required to satisfy the demands of an institutional assessment, can and should lead into the next cyclic process, with its own aims - amongst which active experimentation outstanding from a previous cycle should feature.

This approach was piloted and then practiced for some years in the postgraduate Business School of Edinburgh Napier University, and recently refined and used in the undergraduate Civil Engineering course in the University of Limerick. The results have already been examined and reported (Mina and Cowan, 2019). In this paper we report the results when this method and rationale was presented to first term second year students in the Industrial Design program at one of our institutions.

These students during the first term of their second year are taking their first classes in Industrial Design after finishing the core curriculum at the college level during their first year. Students know the basics of design, critique and related issues from their first-year classes. In the first term of the second year, all students take the following classes in the Industrial Design program: "Fundamentals of Industrial Design" - the first Industrial Design studio; "From Thoughts to Things" - a technological and engineering literacy and critical thinking class that helps the students understand the basics of systems level thinking and know about engineering mindsets and perspectives. The goal is to create better connection between design and engineering. They also take "History of Industrial Design", and the first class in "Human Factors."

This study was conducted in the "From Thoughts to Things" class, which is taught an inquiry-based form. For this study, we introduced and discussed the Kolb cycle and the challenges the students face 
utilizing it. Then we introduced the extended cycle as describe in this paper. The students engaged in in-class group discussions on the whole process. Then the students were asked to think and individually reflect on their ideas, thoughts, and the benefits of the newly proposed extended Kolb cycle to them as designers. They were encouraged to be open, honest, and clear on their impressions of the cycle as well as their thoughts on benefits and usefulness of the cycle.

\section{Industrial design students' reflections on the integrated approach}

\subsection{Analysis}

We collected 60 individual student reflections. The reflections were handwritten and spanned 50 to 300 words, some including diagrams and other visualizations. We utilized thematic analysis (Braun and Clarke, 2006) to address the question "How might the extended Kolb cycle inform the design practice and learning of industrial design students?" The thematic analysis process, adapted from Braun and Clarke (2006), contained five stages that we moved iteratively and recursively between:

1. Reading reflections to familiarize ourselves with the data, both individual reflections and the set of reflections holistically.

2. Generating initial codes that represented potential connections between the extended Kolb cycle and design learning and practice. We utilized no a priori codebook. Codes were generated openly whenever an aspect of design practice was described within a reflection and connected to an aspect of the extended Kolb cycle.

3. Generating themes by exploring patterns (either common or substantive) within or among coded excerpts from student responses. Themes addressed broader ways in which the extended Kolb model might inform design practice or learning.

4. Reviewing themes to ensure they are supported by and are representative of the data. This process involved reviewing coded excerpts that informed the themes and comparing themes to the dataset as a whole.

5. Finalizing themes by generating names and definitions, clarifying the overall narrative the themes demonstrate, and crafting the report with vivid and exemplary excerpts.

\subsection{Results}

We identified three themes that reflected industrial design students' perceptions of the utility of the extended Kolb model for their design practice: (1) aligning with current practices, (2) scaffolding challenging processes and outcomes, and (3) inspiring designerly mindsets. We have also provided an approximate percentage of the students who showed alignments with different items. Because these were short, free response reflections, we would not expect high frequencies for each sub-theme. Even a frequency of $17 \%$ indicates that at least 10 students freely recognized and noted the described application of the modified Kolbian cycle.

\subsubsection{Theme 1: aligning with current practices}

Many students noted that the extended Kolb cycle, or elements thereof, connected to "what [they] do as designers." Several of these students described the extended Kolb cycle as representative of their current, overall design process $(25 \%)$. Others planned to augment their current practices to integrate the model $(50 \%)$. For example, one student wrote:

"In product design you can start by thinking and planning out your design and then you create the design and reflect while you're doing it after you've completed the design you can review it and reflection-on-action and you can see what needs fixed then with the composted reflections you can go back and re-create the design and make it better than your first. Then the process starts over."

In other cases, students noted connections to specific phases of the design process. While students identified connections to several different phases of the design process (e.g., empathizing with users, 
ideation), they most frequently noted connections between (a) reflection-for-action and project planning and scoping (45\%), (b) reflection-in-action and refining process and scope, and (b) reflection-on-action/composting reflections and testing/iterating on designs (18\%). Here, reflectionfor-action aligned with the preliminary work they did exploring the problem space, setting goals, and imagining project trajectories, while the sequence of reflection-on-action to composting reflections aligned with testing and iterating on prototypes and learning from those experiences. In several cases, students described a virtual cycle between these two practices, in which they carried lessons learned about their own practice and the design context into the next design project.

\begin{abstract}
"After a project or prototype is complete, we review the process and draw conclusions on how to improve on the product or how we have learned from our experience. Then going into our next project, we can look back on past projects and use the knowledge and experiences from the past to help us develop a plan that is better than before."
\end{abstract}

\title{
6.2.2. Theme 2: scaffolding challenging processes and outcomes
}

In addition to alignment with current practices, students noted that the extended Kolb model could be used to structure their work such that they more effectively engage in processes and outcomes with which they have typically struggled previously. Some students noted that this scaffolding supports the cyclical practice of project planning, iteration, and learning from experience (23\%) (which other students noted was already established within their current practice). For example, one student wrote:

"The modified model would help me plan my designs better. It also helps me reflect on past design, and better future designs. With having a cycle, it helps keep everything in line and make sure it is well done."

Many students noted the potential benefits toward either empathizing with users or considering a variety and volume of concepts during ideation (18\%). Towards building empathy with users, students noted that the reflective elements throughout the cycle would support deeper and more pervasive perspective-taking. As one student wrote:

"This also helps us understand other people and their design needs better because we are able to see a problem from many different perspectives."

Students described a variety of ways the extended Kolb model could support more fruitful ideation and increased creativity throughout the design process (23\%). Some noted that individual reflections could help them out of "a creative slump" or "performing the same actions over and over again blindly" by orienting them towards new perspectives or helping them consider a variety of new ways to inspire new ideas. Others noted that sequence of regular reflections would keep them engaged in the process and more attuned to the overarching design context, thus inspiring more "intentional" and "interesting" designs. As one student wrote:

"The modified Kolbian model relies almost exclusively on reflection alongside each action. This would help me to become involved in a personal level with ideation and action. By keeping my thought process focused on my creative process, the product will have a full evolution of progression within society and connect with past ideas."

\subsubsection{Theme 3: inspiring designerly mindsets}

Students also noted that in engaging in the extended Kolb model, especially throughout and across their design projects, they would be encouraged to embrace new mindsets that would be useful in their design practice. Echoes of these mindsets (e.g., a focus on taking and applying user perspectives, a focus on creativity and awareness of how to achieve it) can be observed in the previous themes. However, the focus here is on personal changes that would inspire changes in practice rather than changes in practice that support desired personal and project outcomes. In general, the mindsets that students described related to metacognition and deep and holistic mindfulness of the design process and the self within the design process. 
For some students, this mindset manifested as a learning orientation (15\%). Students proposed greater awareness of what happens throughout the design process to support deeper understanding of how one's actions inform the process and can be improved in future work.

"First. It would allow us to reflect on ourselves as designers through analysing our actions, why we did those actions and how they can be improved next time. This helps us refine our general decision-making and design process. Second, it would allow us to understand why certain things happen when we perform an activity. Reflections helps us deal with these consequences in a more effective way and prepare/anticipate for the same consequences."

Other students noted that this mindset would manifest as atonement to and critical awareness of the scope, activities, and progression of a design project, which could inform deeper understanding and orientation towards a purpose, in-the-moment pivots, and realignment with project goals and parameters $(25 \%)$. As one student wrote:

"All the stopping points for reflection are extremely beneficial so you always are thinking about the parameters of the product and what you are doing to achieve them. It shows how experiences can change your design path when you use them to reflect and make sure you are always working towards your goals."

Other students recognized that the mindful, metacognitive mindset could inform both more critically attuned project work and deeper learning from and across projects (38\%).

"It would allow me to take a step back in my mind before, during, and after my design process to think about my expectations as well as the result of my design. Reflection for action creates expectations for myself before designing and can help me understand what I want to get from the experience. Reflection in action allows to take a step back during the process to see what has been accomplished so far and re-evaluate expectations with a wider understanding of the processes taking place. Reflection on action looks back at everything that took place. What goals were met, what was learned, and what could be better in the future. Helps to form future goals for other projects."

\section{Conclusions}

In this paper, we provided new results of design students' reflection on the usefulness of an extended Kolb cycle. The paper summarized present writings about the contributions of various forms of reflection to learning and development. It outlines the difficulties encountered by engineering as well as design students engaging effective reflections in their pursuit of graduate and professional attributes. We have suggested a new framework for programmed integration of various forms of reflection to facilitate better journeys for students' learning and engagement. Finally, we introduced and provide analysis of design students' ideas, and perception about the extended Kolb cycle. The results clearly show that there are benefits to pursue this model and this study for better understanding of design students' learning, growth, and development using the model that was originally designed for engineering students. Students in Design found the cycle refreshing. In the class the students mentioned that they would see natural process for the implementation. They thought that many of the elements that are in the cycle map very closely to their design cycles. They thought that the approach cab facilitates their reflections, expressions, and discussions during and after the design cycle. The majority of the students (more than $60 \%$ ) thoughts that this process can help them created a better-connected story of their design process and their journeys in the whole process. The findings of this paper are aligned and complimentary to some of the valuable learning in multi-disciplinary design education findings (Cascini et al., 2017).

Finally, a postscript. During the period in which this paper was being processed, Cowan was fortuitously engaged in an activity linked to the Design Studio programme at the University of Limerick. This generated a conflated first-hand student review account of the first six weeks of their programme (Cowan, 2020). It centred on linked reflections, whose pedagogical rationale in the course 
structure is outlined. Readers interested in enriching the content of this paper are invited to consult this online paper and to form their own illuminative evaluation of the relevance and validity of the content of the present paper from the data in this citation.

\section{References}

Ashton, J. and Elliott, R. (2007), "Juggling the balls - Study, work, family and play: Student perspectives on flexible and blended heutagogy", European Early Childhood Education Research Journal, Vol. 15 No. 2, pp. 167-181. https://doi.org/10.1080/13502930701321378

Bain, J.D. et al. (2002), Reflecting on Practice: Student Teachers' Perspectives, Post Pressed, Flaxton, Qld.

Brockbank, A. and McGill, I. (1998), Facilitating Reflective Learning in Higher Education, Open University Press, Buckingham.

Boud, D. and Walker, D. (1998), "Promoting reflection in professional courses: The challenge of context", Studies in higher education, Vol. 23 No. 2, pp. 191-206. https://doi.org/10.1080/03075079812331380384

Boud, D., Keogh, R. and Walker, D. (1985), Reflection: Turning experience into learning, Routledge, Abingdon, Oxon.

Bourner, T. (2003), “Assessing reflective learning”, Education + Training, Vol. 45 No. 5, pp. 267-272. https://doi.org/10.1108/00400910310484321

Braun, V. and Clarke, V. (2006), "Using thematic analysis in psychology", Qualitative Research in Psychology, Vol. 3 No. 2, pp. 77-101.

Bruner, J.S. (1986), Actual minds, possible worlds, Harvard University Press, Cambridge, MA.

Bulpitt, H. and Martin, P.J. (2005), "Learning about reflection from the student", Active Learning in Higher Education, Vol. 6 No. 3, pp. 207-217. https://doi.org/10.1177/1469787405057751

Canning, N. and Callan, S. (2010), "Heutagogy: spirals of reflection to empower learners in higher education", Reflective Practice, Vol. 11 No. 1, pp. 71-82. https://doi.org/10.1080/14623940903500069

Cascini, G. et al. (2017), "On the Factors Affecting Design Education Within a Multi-Disciplinary Class", Journal of Integrated Design and Process Science, Vol. 21 No. 2, pp. 21-44. https://doi.org/10.3233/jid-2017-0001

Cowan, J. (2020), "Students' evidenced claims for development of abilities arising from linked reflection-onaction and reflection-for-action", Reflective Practice. https://doi.org/10.1080/14623943.2020.1716709

Cowan, J. (2013), "Facilitating reflective journalling - personal reflections on three decades of practice", Journal of Learning Development in Higher Education, Vol. 5, p. 1, 17.

Cowan, J. (2006), On becoming an innovative university teacher: reflection in action, Society For Research Into Higher Education \& Open University Press, Buckingham \& New York.

Cowan, J. (2004), "Beyond reflection: where next for curricula which concentrate on abilities", Effective Learning and Teaching Engineering, Vol. 202, pp. 19.

Cowan, J. and Stroud, R. (2016), "Composting reflections for development", Reflective Practice, Vol. 17 No. 1, pp. 27-33. https://doi.org/10.1080/14623943.2015.1123684

Cross, N. (1982), "Designerly ways of knowing", Design Studies, Vol. 3 No. 4, pp. 221-227.

Dewey, J. (1910), How we think, D.C. Heath \& Co., Boston, MA.

Day, C. (1993), "Reflection: a necessary but not sufficient condition for professional development", British Educational Research Journal, Vol. 19 No. 1, pp. 83-93. https://doi.org/10.1080/0141192930190107

Francis, H. and Cowan, J. (2008), "Fostering an action-reflection dynamic amongst student practitioners", Journal of European Industrial Training, Vol. 32 No. 5, pp. 336-346. https://doi.org/10.1108/030905 90810877067

Hanson, K. (2011), “'Reflect' - is this too much to ask?”, Reflective Practice, Vol. 12 No. 3, pp. 293-304. https://doi.org/10.1080/14623943.2011.571862

Harrison, J.K., Lawson, T. and Wortley, A. (2005), "Mentoring the beginning teacher: developing professional autonomy through critical reflection on practice", Reflective Practice, Vol. 6 No. 3, pp. 419-441. https://doi.org/10.1080/14623940500220277

Hatton, N. and Smith, D. (1995), "Reflection in teacher education: Towards definition and implementation", Teaching and Teacher Education, Vol. 11 No. 1, pp. 33-49. https://doi.org/10.1016/0742-051X(94)00012-U

Kolb, D.A. (1984)

Knight, P., Yorke, M. and For, S. (2003), Assessment, learning and employability. Society For Research Into Higher Education \& Open University Press, Maidenhead, Berkshire.

Mälkki, K. and Lindblom-Ylänne, S. (2012), "From reflection to action? Barriers and bridges between higher education teachers' thoughts and actions", Studies in Higher Education, Vol. 37 No. 1, pp. 33-50. https://doi.org/10.1080/03075079.2010.492500

Mina, M. and Cowan, J. (2019), "Co-ordinating Kolbian reflections to promote engineers' graduate attributes", 2019 IEEE Frontiers in Education Conference (FIE), Cincinnati, Cleveland. 
Mina, M., Cowan, J. and Heywood, J. (2015), "Case for reflection in engineering education and an alternative", 2015 IEEE Frontiers in Education Conference (FIE), Erie, Pennsylvania.

Mina, M. (2015), “Application of Reflective Thinking Exercises in both Technological Literacy and Standard Engineering Courses", 2015 ASEE Annual Conference \& Exposition, Seattle, Washington.

Moon, J.A. (2004), A handbook of reflective and experiential learning: theory and practice, RoutledgeFalmer, London.

Moon, J.A. (1999a), Learning journals: a handbook for academics, students and professional development, Kogan Page, London.

Moon, J.A. (1999b), Reflection in Learning and Professional Development, Kogan Page, London.

Morton, J.P. (2009), "Critical reflections from a neophyte lecturer in higher education: a self-narrative from an exercise 'physiologist'!", Reflective Practice, Vol. 10 No. 2, pp. 233-243. https://doi.org/10.1080/14623 940902786230

O'Connell, T.S. and Dyment, J.E. (2011), “The case of reflective journals: is the jury still out?", Reflective Practice, Vol. 12 No. 1, pp. 47-59. https://doi.org/10.1080/14623943.2011.541093

Quayle, M. and Parerson, D. (1989), "Techniques for encouraging reflection in design”, Journal of Architectural Education, Vol. 42 No. 2, pp. 3-42.

Quilligan, M., Phillips, D. and Cosgrove, T. (2017), "Encouraging and facilitating students' creativity in problem solving in civil engineering at the University of Limerick", Creative Academic Magazine (Online), Vol. 7c, pp. 80-93.

Ryan, M. (2010), "Improving reflective writing in higher education: a social semiotic perspective", Teaching in Higher Education, Vol. 16 No. 1, pp. 99-111. https://doi.org/10.1080/13562517.2010.507311

Samuels, M. and Betts, J. (2007), "Crossing the threshold from description to deconstruction and reconstruction: using self-assessment to deepen reflection”, Reflective Practice, Vol. 8 No. 2, pp. 269-283. https://doi.org/ $10.1080 / 14623940701289410$

Schön, D.A. (1987), Educating the Reflective Practitioner, Jossey-Bass, San Francisco, CA.

Schön, D.A. (1984), "The Architectural Studio as an Exemplar of Education for Reflection-in-Action", Journal of Architectural Education, Vol. 38 No. 1, p. 2. https://doi.org/10.1080/10464883.1984.10758345

Sepp, L.A. et al. (2015), "On an upward trend: Reflection in engineering education", 2015 ASEE Annual Conference \& Exposition, Seattle, WA.

Smyth, J. (1989), "Developing and Sustaining Critical Reflection in Teacher Education", Journal of Teacher Education, Vol. 40 No. 2, pp. 2-9. https://doi.org/10.1177\%2F002248718904000202

Svarovsky, G. and Shaffer, D.W. (2006), "Design meetings and design notebooks as tools for reflection in the engineering design course", 36th ASEE/IEEE Frontiers in Education Conference, San Diego, CA.

Turns, J. et al. (2014), "Integrating Reflection on Experience into Engineering Education", 2014 ASEE Annual Conference \& Exposition, Indianapolis, IN.

Thompson, N. and Pascal, J. (2012), "Developing critically reflective practice”, Reflective Practice, Vol. 13 No. 2, pp. 311-325. https://doi.org/10.1080/14623943.2012.657795

Van Manen, M. (1991), The Tact of Teaching: The Meaning of Pedagogical Thoughtfulness, SUNY Press, New York.

Vygotsky, L. (1986), Thought and Language, MIT Press, Cambridge, MA.

Williams, R. and Grudnoff, L. (2011), "Making sense of reflection: a comparison of beginning and experienced teachers' perceptions of reflection for practice", Reflective Practice, Vol. 12 No. 3, pp. 281-291. https://doi.org/10.1080/14623943.2011.571861

Yorke, M. and Knight, P.T. (2006), Embedding Employability into the Curriculum: Learning \& Employability Series 1, Higher Education Academy, Heslington, York.

Zeichner, K.M. and Liston, D.P. (1996), Reflective Teaching: An Introduction, Lawrence Erlbaum Associates, Mahwah, NJ.

Zhu, X. (2011), "Student teachers' reflection during practicum: Plenty of action, few in action", Reflective Practice, Vol. 12 No. 6, pp. 763-775. https://doi.org/10.1080/14623943.2011.601097 